\title{
ANALISIS PEMANFAATAN TEKNOLOGI INFORMASI TERHADAP EFESIENSI KERJA PEGAWAI DI BANK LAMPUNG
}

\author{
Husna Purnama ${ }^{(1)}$, Iwan Zulfikar ${ }^{(1)}$, Tia Rama Destia ${ }^{(1)}$ \\ (1) Universitas Sang Bumi Ruwa Jurai \\ *email korespondensi: tiarama700@gmail.com
}

\begin{abstract}
Abstrak. Kemampuan pegawai Bank dalam pemanfaatan teknologi informasi merupakan salah satu peningkatan kualitas pelayanan perbankan. Tujuan penelitian ini untuk mengetahui pemanfaatan teknologi informasi terhadap efesiensi kerja pegawai di Bank Lampung. Metode penelitian yang digunakan dalam penelitian ini menggunakan metode penelitian deskriptif kuantitatif. Metode pengumpulan data yang digunakan berupa data primer dan data sekunder. Teknik pengumpulan data yang digunakan adalah observasi dan quisioner. sampel yang digunakan dalam penelitian ini berjumlah 27 karyawan Bank Lampung KCP, Kalianda Lampung Selatan. Hasil penelitian menunjukan bahwa pemanfaatan teknologi informasi memiliki kontribusi dan berpengaruh signifikan terhadap kualitas pelayanan Bank Lampung KCP. Kalianda, nilai pengaruh pemanfaatan teknologi informasi terhadap kualitas pelayanan Bank Lampung KCP Kalianda dapat ditunjukkan dengan nilai $\mathrm{R}$ square $=0,319$ atau sebesar $31,9 \%$ sedangkan sisanya sebesar $68,1 \%$ dipengaruhi oleh faktor lain yang tidak diteliti dalam penelitian ini.
\end{abstract}

Kata kunci: Teknologi Informasi, Efesiensi Kerja

Abstract. The ability of Bank employees to use information technology is one of the improvements in the quality of banking services. The purpose of this study was to determine the use of information technology on the work efficiency of employees at Bank Lampung. The research method used in this research is descriptive quantitative research method. Data collection methods used in the form of primary data and secondary data. Data collection techniques used are observation and questionnaires. The sample used in this study amounted to 27 employees of Bank Lampung KCP, Kalianda South Lampung. The results showed that the use of information technology had a significant contribution and effect on the service quality of Bank Lampung KCP. Kalianda, the value of the influence of the use of information technology on the service quality of Bank Lampung KCP Kalianda can be shown by the value of $R$ square $=0.319$ or $31.9 \%$ while the remaining $68.1 \%$ is influenced by other factors not examined in this study.

Keywords: Information Technology, Work Efficiency

\section{PENDAHULUAN}

Kemajuan dan perkembangan teknologi yang diiringi dengan perkembangan sistem informasi berbasis teknologi terjadi begitu pesat di era globalisasi ini. Keberhasilan suatu sistem berkaitan dengan kinerja yang dimiliki oleh sistem tersebut. Faktor lain yang mendukung keberhasilan dari suatu sistem yaitu kinerja individu. Pengertian dari kinerja individu itu sendiri adalah kemampuan individu untuk melakukan sesuatu dengan berhasil dan efisien pada suatu perusahaan. Ada beberapa hal yang dapat mempengaruhi kinerja individu yaitu efektivitas sistem informasi akuntansi, kemampuan teknis pemakaian sistem informasi dan pemanfaatan teknologi informasi.

Aktivitas yang dijalankan masyarakat sebagian besar berhubungan dengan uang yang pada akhirnya melibatkan dunia 
perbankan, karena itu perbankan memegang peranan penting dalam kehidupan masyarakat sehari-hari. Berdasarkan jenis pembayaran jasa, bank di Indonesia dibedakan menjadi dua jenis bank, yaitu bank yang melakukan usaha berdasarkan prinsip bunga, disebut Bank Konvensional dan bank yang melakukan usaha berdasarkan prinsip bagi hasil, disebut dengan Bank Syariah. Kemudahan yang diberikan oleh pemerintah terkait dengan syarat-syarat untuk mendirikan bank, menambah jumlah bank yang berdiri baik itu bank konvensional maupun bank syariah.

Adanya transformasi digital membuat layanan perbankan yang tersedia bagi masyarakat berbasis teknologi baru (Drasch et.al,2018). Jika dahulu bank hanya dianggap sebagai sarana untuk menyimpan uang dan sumber dalam mendapatkan pembiayaan atau kredit, saat ini bank tidak hanya melakukan fungsi dasarnya sebagai perantara keuangan, tetapi juga sebagai penasihat keuangan untuk nasabahnya melalui penerapan digitalisasi. nasabah juga dipermudah karena bisa berinteraksi secara langsung melalui perangkat seluler yang dimilikinya. (Lipton et. al, 2016). Penerapan digitalisasi dinilai dapat mempengaruhi efektiiviast kerja pegawai sektor keuangan dan perbankan.

Suatu perusahaan atau instansi selalu berusaha agar karyawan yang terlibat didalamnya dapat mencapai efektivitas kerja. Keberhasilan organisasi dalam mencapai tujuannya dimulai dari keberhasilan masing-masing karyawan yang bersangkutan. Dengan kata lain efektivitas suatu organisasi atau perusahaan dapat tercapai apabila masing-masing karyawan dapat tepat mencapai sasaran yang dikehendaki.

Bank mempunyai peran dalam menghimpun dana masyarakat karena merupakan lembaga yang dipercaya oleh masyarakat dari berbagai macam kalangan dalam menempatkan dananya secara aman. Percaya bahwa dana yang ditempatkan di bank keaamanannya lebih terjamin dibandingkan ditempatkan dilembaga lain.disisi lain bank berperan dalam menyalurkan dana kepada masyarakat. Bank merpakan lembaga yang memberikan pinjaman kepada masyarkat yang membutuhkan dana.masyarakat dapat secara langsung mendapat pinjaman dari bank, sepanjang masyarakat mengunaka dana tersebut dapat memenuhi persyaratan dari bank. Pada padasarnya bank mempunyai peran dari dua sisi yaitu menghimpun dana yang berasal dari masyarakat yang sedang kelebihan dana dan menyalurkan dana kepada masyarakat yang membutuhkan dana untuk memenuhi kebutuhannya. Kegiatan menyalurkan dana kepada masyarakat, disamping merupakan aktivitas yang dapat menghasilkan keuntungan,juga untuk memanfaatkan dana yang idle (idle fund) karena bank telah membayar sejumlah tertentu atas dana yang dihimpunya. Pada akhir bulan atau pada saat tertentu bank akan mengeluarkan biaya atas dana yang telah dihimpun dari masyarakat yang telah menyimpan dananya di bank. Dalam pelaksanaan pekerjaan, seringkali diperlukan alat bantu yang dapat dimanfaatkan oleh karyawan. Alat bantu tersebut berupa Teknologi informasi. Teknologi informasi saat ini terus berkembang dan semakin canggih dimana teknologi dijadikan sebagai penunjang berbagai aktivitas penting yang dilakukan manusia. Dengan penggunaan teknologi informasi yang tepat bagi karyawan, baik berupa hardware, software maupun sarana lainnya tentu akan membantu meringankan karyawan dalam menyelesaikan tugasnya. Ketersediaan komputer dan berbagai macam perangkat lunak yang mudah dioperasikan maka karyawan dapat dengan 
Kurangnya pengetahuan teknologi informasi seringkali juga menyebabkan kinerja karyawan menurun. Seperti yang terjadi pada karyawan Bank Lampung KCP Kalianda. Banyak karyawan kurang memahami teknologi informasi yang ada sehingga menurunkan kinerja karyawan. Berdasarkan fakta tersebut, teknologi informasi dalam lingkungan pekerjaan mempengaruhi kinerja karyawan, sehingga dalam pemanfaatannya harus optimal dan sesuai dengan yang dikerjakan oleh karyawan sehingga produktivitas karyawan pun meningkat.Selain Teknologi Informasi, sistem yang digunakan didalamnya merupakan salah satu perangkat lunak yang wajib di gunakan dalam perusahaan. Perkembangan Sistem Informasi saat ini semakin pesat, perubahan yang terjadi dapat dilihat pada kecenderungan orang atau suatu bisnis untuk selalu menggunakan suatu sistem yang terkomputerisasi yang bertujuan untuk mengefektifkan kerja dan mengefisiensikan waktu untuk meningkatkan keuntungan bisnis.

Sistem informasi juga dibutuhkan karyawan dalam menjalankan pekerjaannya. Seringkali sistem yang diterapkan kurang

\section{METODE PENELITIAN}

Metode penelitian yang akan digunakan adalah metode analisis kualitatif dan analisis kuantitatif yaitu dengan melakukan penelitian lapangan dan dilakukan uji reliabilitas, uji validitas terlebih dahulu. Populasi dari penelitian ini adalah seluruh pegawai bank Lampung KCP Kalianda sebanyak 27 orang. Teknik pengumpulan data melalui observasi, kuesioner, dan efisien atau kurang memberikan hasil yang akurat, sering terjadinya error dari sistem yang diterapkan, maka akan berdampak juga pada karyawan yang menggunakan sistem tersebut. Selain itu pengoperasian system yang rumit, dan juga dengan kemampuan karyawan yang rendah dalam pengoperasian sistem informasi tersebut juga menjadi penghambat pekerjaan para karyawan.

Berdasarkan pra penelitian yang dilakukan penulis di Bank Lampung ditemukan beberapa fenomena dimana banyak pegawai bank Lampung kurang mampu memanfaatkan kemajuan teknologi informasi sehingga mengganggu pelayanan perbankan, banyak pegawai bank yang belum mampu dan memahami penggunaan teknologi informasi perbankan sehingga pekerjaan yang dilakukan kurang efektif dalam penyelesaiannya. Berdasarkan tabel 1, dapat disimpulkan bahwa presentasi hasil evaluasi pelaksanaan kegiatan selama tahun 2021 selalu mengalami penurunan, hal ini menyebabkan kinerja pegawai menurun. Sehingga peneliti tertarik untuk mengetahui Pemanfaatan Teknologi Informasi Terhadap Kualitas Pelayanan Bank Lampung KCP Kalianda.

dokumentasi. Analisis kuantitatif dengan metode statistik yang digunakan adalah analisis regresi linear sederhana.

\section{HASIL DAN PEMBAHASAN}

Pada penelitian ini diambil 27 orang karyawan dengan karakteristik responden. Karakteristik pegawai yang menjadi subyek dalam penelitian ini menurut jenis kelamin ditunjukkan dalam Tabel 1 dibawah ini :

\begin{tabular}{lllr}
\multicolumn{4}{l}{ Tabel 2. } \\
\hline No & Ketribusi Frekuensi Responden Berdasarkan Jenis Kelamin & Frekuensi & Persentase \\
\hline 1 & Laki-Laki & 15 & $55 \%$ \\
2 & Perempuan & 12 & $45 \%$ \\
Total & & 27 & $100,0 \%$ \\
\hline
\end{tabular}


Berdasarkan tabel karakteristik responden menurut jenis kelamin di atas, dapat diketahui bahwa sebanyak 15 karyawan $(55 \%)$ berjenis kelamin laki-laki dan sebanyak 12 karyawan (45\%) berjenis kelamin perempuan. Karakteristik pegawai yang menjadi subyek dalam penelitian ini menurut usia ditunjukkan dalam Tabel 2 dibawah ini :

Tabel 3. Karakteristik Responden Berdasarkan Usia

\begin{tabular}{lllr}
\hline No & Keterangan & Frekuensi & Persentase \\
\hline 1 & $21-30$ Tahun & 4 & $15 \%$ \\
2 & 31- 40 Tahun & 13 & $48 \%$ \\
3 & 41- 50 Tahun & 7 & $26 \%$ \\
4 & $>50$ Tahun & 3 & $11 \%$ \\
Total & & 31 & $100,0 \%$ \\
\hline
\end{tabular}

Berdasarkan tabel karakteristik memprediksi atau mengestimasi nilai responden berdasarkan usia di atas, variabel dependen apabila nilai variabel memperlihatkan bahwa sebanyak 4 independen yang diketahui mengalami karyawan (15\%) berusia antara 21-30 tahun, kenaikan atau penurunan. Hasil dari sebanyak 13 karyawan (48\%) berusia antara penghitungan statistik regresi linier 31-40 tahun, sebanyak 7 pegawai (26\%) sederhana pengaruh pemanfaatan teknologi berusia antara 41 - 50 tahun dan sebanyak 3 informasi terhadap kualitas pelayanan PT. karyawan (11\%) berusia lebih dari 50 tahun. Bank Lampung KCP Kalianda adalah Analisis linier sederhana bertujuan untuk sebagai berikut:

Tabel 4. Hasil Perhitungan Regresi Linier Sederhana

Pengaruh Pemanfaatan Teknologi Informasi terhadap Kualitas Pelayanan

\begin{tabular}{|c|c|c|c|c|c|c|}
\hline \multirow{2}{*}{\multicolumn{2}{|c|}{ Model }} & \multicolumn{2}{|c|}{$\begin{array}{c}\text { Unstandardized } \\
\text { Coefficients }\end{array}$} & \multirow{2}{*}{$\begin{array}{c}\text { Standardized } \\
\text { Coefficients }\end{array}$} & \multirow[b]{2}{*}{$\mathrm{t}$} & \multirow[b]{2}{*}{ Sig. } \\
\hline & & B & Std. Error & & & \\
\hline 1 & (Constant) & 17.654 & 7.478 & & 2.361 & .026 \\
\hline & Tekn.Informasi & .584 & .171 & .565 & 3.420 & .002 \\
\hline
\end{tabular}

a. Dependent Variable: Pelayanan

Berdasarkan tabel 4 menunjukkan nilai konstanta atau coefficient constant sebesar 17.654. model persamaan regresi linear sederhana sebagai berikut: Y (Kualitas pelayanan $)=17.654+0,584($ Pemanfaatan Teknologi Informasi). Koefisien regresi pemanfaatan teknologi informasi (X) adalah sebesar 0,584 mengandung arti bila terjadi kenaikan 1 nilai pada variabel pemanfaatan teknologi informasi maka akan meningkatkan kualitas pelayanan sebesar 0.584 artinya pengaruh pemanfaatan teknologi informasi terhadap kualitas pelayanan positif. signifikasi sebesar 0.000 $<0.005$ mengandung arti pengaruh pemanfaatan teknologi informasi terhadap kualitas pelayanan signifikan.

Layanan perbankan berbasis teknologi informasi yang umumnya dikenal sebagai electronic banking/digital banking, memudahkan nasabah untuk melaksanakan transaksi keuangan melalui berbagai delivery channel antara lain Automatic Teller Machine (ATM), Electronic Data 
Capture (EDC), internet banking, Short Messaging Service (SMS) banking, phone banking, maupun mobile banking (Otoritas Jasa Keuangan, 2016). Perkembangan ebanking yang diawali dengan pembukaan ATM yaitu memiliki fungsi utama untuk penarikan tunai. Selanjutnya diikuti dengan penyelenggaraan EDC yang berfungsi melayani transaksi pembayaran nasabah. Meningkatnya transaksi melalui channel mobile banking, berdampak pada penurunan transaksi yang dilakukan di kantor cabang. Hal ini menunjukkan kebiasaan/ behavior masyarakat yang mulai mengarah kepada transaksi elektronik perbankan melalui perangkat digital yang memberi kemudahan bagi nasabah. Perkembangan layanan perbankan digital ini didorong oleh hal-hal sebagai berikut: adanya perkembangan teknologi informasi yang pesat, perubahan gaya hidup masyarakat sesuai perkembangan teknologi informasi, adanya kebutuhan masyarakat terhadap layanan perbankan yang efektif, efisien, dapat diakses dari manapun dan kapanpun,komprehensif, serta mudah, kompetisi industri perbankan untuk memberikan layanan sesuai dengan kebutuhan masyarakat, kebutuhan perbankan terhadap operasional yang efisien dan terintegrasi. Pemanfaatan teknologi informasi perbankan melalui layanan digital perbankan akan meningkatan kualitas layanan perbankan, semakin tinggi teknologi perbankan maka akan memudahkan pelayanan yang diberikan bank kepada nasabah.

\section{KESIMPULAN}

Berdasarkan hasil penelitian diperoleh kesimpulan sebagai berikut: Hasil pengujian hipotesis pengaruh pemanfaatan teknologi Informasi terhadap kualitas pelayanan Bank Lampung KCP Kalianda menunjukan bahwa nilai $\mathrm{t}$ hitung sebesar 3.420 dan $\mathrm{t}$ tabel pada $\mathrm{n}=27$ dan $\alpha=0,05$ diperoleh $\mathrm{t}$ tabel $=1,703$ dan tingkat dengan demikian $\mathrm{t}$ hitung > t tabel atau $3.420>1,703$ hal ini berarti pemanfaatan teknologi informasi memiliki kontribusi dan berpengaruh signifikan terhadap kualitas pelayanan Bank Lampung KCP. Kalianda. nilai pengaruh pemanfaatan teknologi informasi terhadap kualitas pelayanan Bank Lampung KCP Kalianda dapat ditunjukkan dengan nilai $\mathrm{R}$ square $=0,319$ atau sebesar $31,9 \%$ sedangkan sisanya sebesar $68,1 \%$ dipengaruhi oleh faktor lain yang tidak diteliti dalam penelitian ini.

\section{DAFTAR PUSTAKA}

Aaker. 2016. Pengertian Kepuasan Kerja. Ramadan Bandung.

Ainun, Fitriani Ratna. 2017. Evaluasi Kinerja Keuangan Bank-Bank Pemerintah. Jakarta.

Ambar Teguh Sulistiyani dan Rosidah, 2017, Manajemen Sumber Daya Manusia,. Graha Ilmu: Yogyakarta.

Anwar Prabu Mangkunegara. 2016. Evaluasi Kinerja SDM. Eresco, Jakarta

Effendy, 2015. Efektivitas Kerja di dalam Organisasi. Bandung : Alfabeta.

Ermaya Suradinata, 2013, Manajemen Sumber Daya Manusia, Ramadan Bandung.

Fahmi, Irham. 2011. Manajemen Teori, Kasus dan Solusi. Bandung : Alfabeta.

\begin{tabular}{|c|c|c|}
\hline Gomes & $\begin{array}{r}\text { Faustino } \\
\text { Manajemen }\end{array}$ & $\begin{array}{r}\text { Cardoso, } \\
\text { Sumber }\end{array}$ \\
\hline & $\begin{array}{l}\text { Manusia, } \\
\text { Yogyakarta2 }\end{array}$ & $\begin{array}{l}\text { Penerbit } \\
01\end{array}$ \\
\hline
\end{tabular}

Handayaningrat, 2017. Pengukuran Efektivitas Kerja Pegawai. Cetakan 
Ketiga, Alih Bahasa Agus Dharma, Erlangga, Jakarta

Hariandja, Marihot T.E, 2012. Manajemen

Sumber Daya Manusia. Jakarta: Grasindo.

Hersey, Paul dan Ken Blanchard. 2017. Manajemen Perilaku Organisasi : Pendayagunaan Sumberdaya Manusia, Cetakan Ketiga, Alih Bahasa Agus Dharma, Erlangga, Jakarta

Irham. 2017. Pengukuran Kinerja. Salemba Empat, Jakarta

Kartini Kartono. 2016. Psikologi Umum. Bandung: CV Mandar Maju.

Kotler, Philip. 2013. Manajemen Pemasaran, Analisa perencanaan, Implementasi dan control, Edisi Kesembilan, Jilid 1 dan jilid 2, Jakarta.

Lupiyoadi, Rambat, 2016, Manajemen Pemasaran Jasa, Salemba Empat, Jakarta

Malayu S.P. Hasibuan. 2018. Pengukuran Kinerja. Jakarta: Rineka Cipta

Moekijat, 2016, Latihan dan Pengembangan Layanan Pegawai, Bandung

Mondy, R.W., \& Noe, R.M. 2012. Human Resources Management $9^{\text {th }} \mathrm{ed}$. Massachusetts; Prentice-Hall.

Musanef, 2014. Perilaku Organisasi. Rineka Cipta. Jakarta.

Richard M. Steers. 2018 , Efektifitas Kerja Pegawai. Jakarta: Rineka Cipta

Prawirasentono, 2017. Faktor - faktor yang mempengaruhi kinerja. Jakarta: Rineka Cipta

Payne, 2019."Service Marketing Pemasaran Jasa", Andi Yogyakarta.
Rivai. 2013. Penilaian Kinerja Seseorang Pegawai Dalam Organisasi. Cetakan Kesatu, CV. Alfabeta Bandung.

Robbins: 2017. Fungsi Kinerja. Jakarta: Rineka Cipta

Suradinata. 2014. Pengertian Efektivitas Kerja. Salemba Empat, Jakarta

Singarimbun, Masri, 2016. Metode Penelitian Survei, Jakarta: LP3ES.

Stephens P. Robbins, 2017. Prinsip-prinsip Perilaku Organisasi, alih bahasa oleh Halida dan Dewi Sartika, Edisi Kelima, Erlangga.

Sedarmayanti, 2010. Manajemen Sumber Daya Manusia. Cetakan Kedua, CV. Alfabeta Bandung.

Sugiyono, 2008, Statistika Untuk Penelitian, Cetakan Keenam, CV. Alfabeta Bandung.

Sulistiyani dan Rosidah. 2018. Definisi Kinerja. Salemba Empat, Jakarta

Suharsimi Arikunto, 2018. Prosedur Penelitian Suatu Pendekatan Praktek, Jakarta, Rineka Cipta.

Sudjana, 2008, Metode Penelitian Bisnis, Penerbit Alphabeta, Bandung.

Sugiyono, 2008, Metode Penelitian Statistik, Jakarta, Rineka Cipta.

Soekidjo Notoatmodjo. (2005). Metodologi penelitian kesehatan. Jakarta: Rineka Cipta.

Widodo. 2018. Psikologi Belajar. Jakarta: Rineka 